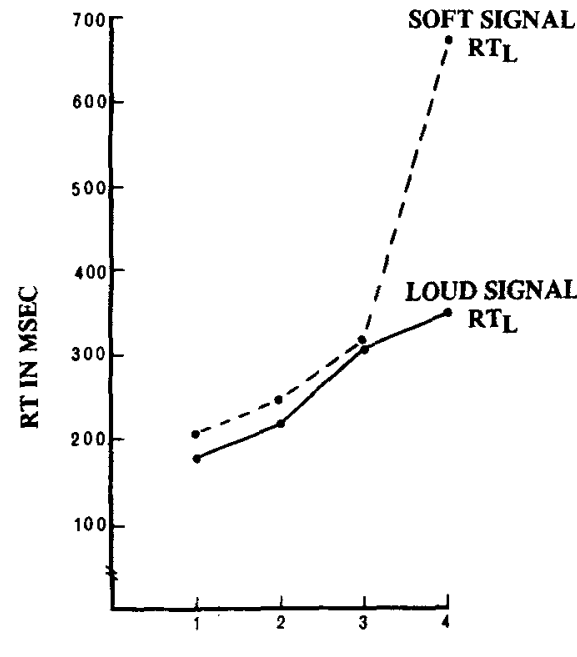

SPEED RATING ( 1 = FAST $)$

Fig. 1. Reaction time and speed rating for loud and soft stimuli.

the within-category differences were $29 \mathrm{msec}$ for Categories 1 and 2. DISCUSSION

First, we can say that Ss can rate their speed of reaction in a meaningful way. Such ratings may carry important implications for the practical measurement of RT and hence for theoretical notions. An obvious extension of the approach adopted here would be to examine the form of the reaction-time distribution when it is decomposed by extracting readings from the longer categories as rated.

Second, the difference in the distribution of speed ratings between the two intensities suggests that $S$ s are aware of at least some of the intensity-dependent delay in RT. This suggests that the detection-time model of intensity effects in RT is inadequate to account for the auditory data. Roufs (1966) felt that the phenomenological state of perceiving and the triggering of a simple reaction were one and the same process. He says, "...the visual latency is the difference in time between the onset of a stimulus and the moment the subject is aware of it .... As this delay is an integral part of the reaction time, the measurement of the latter provides a mean to find the variation in latency as a function of stimulus luminance." This does not appear to be true for audition. Other evidence, from the effects of auditory stimulus intensity on phenomenal simultaneity, seems also to point to the inadequacy of a simple phenomenological model to account for auditory intensity effects on simple RT (Sanford, unpublished data).

In conclusion, it seems possible to obtain reaction-time speed ratings, and

these may be useful in separating sensory Just as in psychophysics, confidence ratings are meaningfully related to obtained scores, so may speed ratings be of value in reaction-time work. Some current research is being aimed at the use of a more continuous rating system for speed in a variety of reaction-time situations.

REFERENCES
BERNHARD, C. G. Contributions to the
neurophysiology of the optic pathway. Acta
Physiologica Scandinavica, 1940, 1,
Supplement 1.

\title{
Memory and conservation
}

\author{
FRANK B. MURRAY and R. BARKER BAUSELL \\ University of Delaware, Newark, Del. 19711
}

Minimal support for the Genevan hypothesis that memory of stimuli is often dependent upon the operational schemes that underlie the cognition of those stimuli was found. Specifically, number conservation and not length or amount conservation was found to be significantly related to recall and recognition of the conservation stimuli. The relationship was due to nonconservers' retention failures and not to conservers' ability to remember correctly. Seriation and water-level performance was related to recall of the appropriate stimuli. Ninety-two first and second graders of average intelligence were studied.

A recent hypothesis from Geneva (Piaget, 1967; Piaget et al, 1968; Inhelder, 1969) stated that the mnemonic code for the retention of many simple stimuli is critically dependent upon the operational schemes of intelligence that are related to the cognition of those stimuli. In some cases the mnemonic code may be the operational scheme (e.g., seriation). Thus, as the various operational schemes develop and mature, it is possible that memories of stimuli encoded in those schemes would also develop and mature. There is evidence (Altemeyer, Fulton, \& Berney, 1969) that memories of a serially ordered array of sticks actually improved somewhat over a 6-month period and that the degree of improvement was closely related to improvement in the child's ability to arrange sticks in serial order (Inhelder, 1969). It has also been demonstrated that not every kind of "memory encoding related to operativity will lead to progress with a sufficient interval of time [Inhelder, 1969, p. 362]." To date there is limited evidence for memory change in the direction of operational maturity for serial order, double serial order (M), water level in a tilted bottle, and some causal relationships.

Since a prerequisite for memory improvement is the relationship between operativity and immediate memory, the present investigation examined the relationship between conservation of amount, number, and length and the child's immediate recall and recognition memory of the transformed conservation stimuli.

\section{SUBJECTS}

There were 92 children in all, 48 first graders, with a mean age of 78.67 months $(\mathrm{SD}=4.43)$ and a mean IQ of 102.3 $(S D=11.03)$, and 44 second graders, with a mean age of 93 months $(\mathrm{SD}=7.58)$ and a mean IQ of $103.1(S D=11.07)$.

\section{PROCEDURE}

As a group in their classrooms, Ss were given a booklet in which were depicted by line drawings the following operational problems: (1) Conservation of amount in three scenes, one under the other on a page (two equal glasses of liquid, each glass being poured into either a tall narrow glass or a short wide glass, the tall narrow glass and the short wide glass with correct and different liquid levels); (2) conservation of length in two scenes, one under the other on the page (two equal sticks, one dark and one light, and one above the other, with the dark stick drawn so that one-third of it extended to the right of the other stick); and (3) conservation of number in two scenes on the page (a row of five circles above a row of equal length of five cups; the row of five cups was longer than the row of five circles). To the right of the top and bottom scenes for each problem were the words "yes" and "no," which the 
Table 1

Number of Conservers and Nonconservers Who Recalled and Recognized the Conservation Stimuli Correctly (R) and Incorrectly (W) $(N=92)$

Immediate Memory

\begin{tabular}{|c|c|c|c|c|c|c|c|c|c|c|c|c|}
\hline \multirow[b]{3}{*}{ Operativity } & \multicolumn{4}{|c|}{ Amount } & \multicolumn{4}{|c|}{ Length } & \multicolumn{4}{|c|}{ Number } \\
\hline & \multicolumn{2}{|c|}{ Recall } & \multicolumn{2}{|c|}{ Recognize } & \multicolumn{2}{|c|}{ Recall } & \multicolumn{2}{|c|}{ Recognize } & \multicolumn{2}{|c|}{ Recall } & \multicolumn{2}{|c|}{ Recognize } \\
\hline & $\mathrm{R}$ & $w$ & $\mathbf{R}$ & $w$ & $\mathbf{R}$ & W & $R$ & W & $\mathbf{R}$ & W & $\mathrm{R}$ & $w$ \\
\hline Conserver & 11 & 19 & 24 & 5 & 17 & 17 & 29 & 5 & 18 & 20 & 22 & 16 \\
\hline Nonconserver & 22 & 40 & 48 & 15 & 24 & 34 & 38 & 20 & 10 & 44 & 16 & 38 \\
\hline
\end{tabular}

children were directed to circle in answer to the questions of whether there was the same amount to drink in each glass, whether the sticks were the same length, and whether there were the same number of balls as cups. If the child circled "no," he was asked to circle the item that was greater in amount, length, or number. $\mathrm{E}$ was at the front of the classroom and, in his description of each problem, pointed to the appropriate stimuli on large drawings of the ones the children had in their booklets.

The booklets also contained a serial order and a water-level problem. In the serial-order problem, Ss were required to copy on a horizontal line seven vertical lines, each one about $1 / 2$ in. shorter than the one to its left. In the water-level problem, Ss were required to draw the water-level line on a tilted bottle, which was below a drawing of an upright bottle with an horizontal water line.

After Ss had answered the conservation and two other problems, they were directed to draw on blank pages in the booklet (1) the jars into which the water was poured, (2) the sticks after one was moved, (3) the rows of balls and cups after one was moved, (4) the row of sticks, and (5) the tilted jar and water level. After these problems, Ss were required to select stimuli that they remembered from four altematives for the conservation stimuli and five for the serial-order stimuli.

There is evidence (Murray, 1970) that conservation performance is unaffected by whether the conservation stimuli are presented as line drawings, as in the booklet, or as actual objects.

\section{RESULTS}

The number of $\mathrm{Ss}$ who conserved, or said the stimuli were the same after the transformation was drawn and described, and those who did not conserve are shown in Table 1, along with the numbers of conservers and nonconservers who recalled and recognized the stimuli correctly and incorrectly. There was a significant association between conservation of number and recall $\left(\chi^{2}=7.46, p<.01\right)$ and recognition $\left(\chi^{2}=6.23, p<.02\right)$ of the number of stimuli. The associations between the conservations of amount and length of the stimuli were not significant by chi square. The criteria for correct recall were that the drawings be correct in all critical aspects, i.e., (1) jars differed in width and height, (2) equal sticks and dark stick to the right, (3) correct number of circles and cups and longer row of cups, (4) correct number of sticks and seriated in correct direction, and (5) correct height and level of water.

Conservation, as usual, was related to age, in that there were significantly more conservers and fewer nonconservers in Grade 2 than in Grade 1 for amount $\left(\chi^{2}=15.03, p<.001\right)$, for length $\left(\chi^{2}=5.13, \quad p<.05\right)$, and for number $\left(\chi^{2}=11.04, p<.001\right)$. Performance in the serial-order task was also related to grade level, with significantly more correct copies of the array in second grade, etc. $\left(\chi^{2}=3.87, \mathrm{p}<.05\right)$. In the water jar problem, since all but five second graders drew the water level incorrectly on the tilted jar, it was not possible to determine the age relationship.

Serial-order performance was significantly related to recall $\left(\chi^{2}=11.57\right.$, $\mathrm{p}<.001)$ and insignificantly related to recognition $\left(\chi^{2}=0.07, p>05\right)$ of the array of sticks. Similarly, water-level performance was significantly related to recall $\left(\chi^{2}=28.43, p<.001\right)$ but not to recognition $\left(\chi^{2}=0.50, p>.05\right)$. Of the five Ss who correctly drew the water level, three recalled the figure incorrectly.

The correlations between overall operativity (1 point for each problem correct) and memory ( 1 point for each correct recall, 1 point for each correct recognition) were significant between operativity and recall $(\mathrm{r}=.37$, $\mathrm{df}=90$, $\mathrm{p}<.01)$ and between operativity and recognition $(r=.32, d f=90, p<.01)$.

$$
\text { DISCUSSION }
$$

The usual findings that conservation is related to age and that it is preceded by seriation and followed by horizontality in difficulty were found in this study. In addition, the significant correlations between operativity and recall and recognition provided minimal support for the Genevan memory hypothesis. The association between recall and seriation and water level, although significant and previously reported by Inhelder (1969), is inconclusive in this study, because so few
Ss failed the seriation task (six Ss) or passed the water-level problem (five Ss). Nevertheless, of those Ss who were correct on the seriation task, $84 \%$ correctly recalled the figure and $88 \%$ correctly recognized it, and of those Ss who were incorrect on the water-level problem, $94 \%$ recalled the figure incorrectly and $76 \%$ recognized it incorrectly.

Conservation of number was found to be significantly related to both recall and recognition of the transformed conservation stimuli. However, this relationship appeared to be due to the nonconservers' failure to remember and not to the conserver's ability to remember correctly. In all the conservation problems, the apparent presence of the operational schemes did not guarantee the correct recall of the conservation stimuli, since conservers were as likely to recall incorrectly as they were to recall correctly. The theoretical dependence of memory on the operational schemes is jeopardized by failure of conservers and seriators to correctly recall the stimuli.

It has been suggested (Inhelder, 1969) that the strength of the relationship between memory and operativity is proportional to the simplicity of the operational scheme. Although number conservation is among the most primitive conservations, it is difficult to see how the number scheme is simpler than the ones for amount or length. Instead, the reason for the significant association between number memory and conservation and not between the others seems to be the fact that nonconservers of number had more difficulty remembering the appropriate stimuli than did nonconservers of amount or length. This fact is consistent with the reported developmental antagonism between numerical and spatial systems and the apparent interference of these with the memory for stimuli, like the number stimuli, in which these properties are contrasted (Inhelder, 1969).

\section{REFERENCES}

ALTEMEYER, R. A., FULTON, D., \& BERNEY, K. Long-term memory improvement: Confirmation of a finding by Piaget. Child Development, 1969, 40, 845-857.

INHELDER, B. Memory and intelligence in the child. In D. Elkind and J. Flavell (Eds.), Studies in cognitive growth. New York: Oxford University Press, 1969. Pp. 337-363.

MURRAY, F. B. Stimulus mode and the conservation of weight and number. Journal of Educational Psychology, 1970, 61, 287-291.

PIAGET, J. Memory. Lecture given at the University of Minnesota on September 28, 1967. Sponsored by the Department of Special Education, Institute of Child Development, and the Department of Psychology of the University of Minnesota.

PIAGET, J., INHELDER, B., \& SINCLAIR, H. Memoire et intelligence. Paris: Presses Universitaires de France, 1968. 